\title{
Deter o día cunha flor (2009), obra excepcional de Luz Pozo Garza
}

\author{
Deter o día cunha flor (2009), \\ an excellent verse book of Luz Pozo Garza
}

\author{
Aurora LóPez - Andrés Pociña \\ Universidad de Granada \\ auroral@ugr.es apocina@ugr.es \\ [recibido 10/03/2013, aceptado 06/06/2013]
}

\section{RESUMO}

Estudo do poemario, polo momento último publicado, Deter o día cunha flor, da poeta galega Luz Pozo Garza, que formará parte do libro Á procura da poesía. Vida e obra de Luz Pozo Garza, de Aurora López e Andrés Pociña, que está en trámite de edición.

Palabras chave: Luz Pozo Garza, Poesía, Deter o día cunha flor.

López, A. / A. Pociña (2013): “Deter o día cunha flor (2009), obra excepcional de Luz Pozo Garza”, Madrygal (Madr.), 16: 53-61.

\section{RESUMEN}

Estudio del poemario, por el momento último publicado, Deter o día cunha flor, de la poeta gallega Luz Pozo Garza, que formará parte del libro Á procura da poesía. Vida e obra de Luz Pozo Garza, de Aurora López y Andrés Pociña, que está en trámite de edición.

Palabras Clave: Luz Pozo Garza, Poesía, Deter o día cunha flor.

López, A. / A. Pociña (2013): “Deter o día cunha flor (2009), obra excepcional de Luz Pozo Garza”, Madrygal (Madr.), 16: 53-61.

\section{ABSTRACT}

This is a presentation and commentary of Deter o dia cunha flor, at the moment the last verse book of Luz Pozo Garza; it will appear in the next book Á procura da poesía. Vida e obra de Luz Pozo Garza by Aurora López e Andrés Pociña, to be edited proximately.

KEY wORDS: Luz Pozo Garza, Poems, Deter o día cunha flor.

López, A. / A. Pociña (2013): "Deter o día cunha flor (2009), an excellent verse book of Luz Pozo Garza", Madrygal (Madr.), 16: 53-61.

SUMARIO: 1. Poesía e pintura: Luz Pozo Garza e José Valentín. 2. As catro partes do poemario. 3. Dúas notas sobre a recepción de Deter o día cunha flor. 4. Luz Pozo Garza: visión de Deter o día cunha flor. 


\section{POESÍA E PINTURA: LUZ POZO GAR- ZA E JOSÉ VALENTÍN}

Nos primeiros meses de 2009, Baía Edicións publica un fermosísimo libro de versos de Luz Pozo Garza ilustrados, ou para mais precisión, acompañados por gravados de José Valentín, titulado Deter o día cunha flor. A impresión que produce en quen colle o libro nas mans é fulminante, sorprendente pola forma e polo fondo. No comezo, o novo poemario presenta tres curtos textos de Claudio Rodríguez Fer (o poema "A Luz Azul"), de Carmen Blanco (a prosa poética "A Flor do Paraíso") e de Xulio Valcárcel ("Dualidade harmónica"), o terceiro dos cales pensamos que pode servir moi ben de introdución á nosa presentación deste libro:

"Non existe a arte, só os artistas". Se así o aceptamos, podería explicarse a afinidade e irmandade, entre dúas formas de expresión, imaxen e palabra, que se complementan. Antiga é a relación. Xa Simónides de Ceos sostiña que "a poesía é unha pintura falada, e a pintura unha poesía muda". Luz Pozo e José Valentín seguen unha tradición ben nosa: houbo épocas nas que non se concibía a edición dun libro galego sen as correspondentes ilustracións: de Colmeiro, Seoane, Laxeiro, Xohán Ledo...

"Ut pictura poesis erit quae..." escribe Horacio na Epístola aos Pisóns. Lope de Vega fala de "Marino, gran pintor dos oídos e Rubens gran poeta dos ollos". Son porosas as disciplinas artísticas; as interferencias, inevitables. (...) Combinar texto e imaxe foi unha constante en autores como Kafka, tentando "conectar coa maxia primitiva"; D. H. Lawrence, cuestionado por obsceno; W. Blake (A casa da morte, 1975); Charlotte Brontë, máis que notable pintora; Victor Hugo... Cos corenta cumpridos, Hermann Hess descobre que "pintar é unha alegría distinta, faite máis feliz e máis paciente. Non fican negros, manchados, os dedos, senón azuis ou vermellos".

Relación constantemente renovada, a da pintura e a poesía, que volvemos atopar nesta obra, síntese fecunda de dúas achegas a un todo harmónico. Deter o día cunha flor, este é o título, enunciado-propósito, do libro de Luz Pozo Garza e José Valentín. (Valcárcel 2009: s. p.)
O desexo de mesturar poesía e pintura non é cousa estraña en Luz Pozo Garza, como demostra a miúdo e moi ben, por exemplo, en cada volume de Clave Orión, unha das revistas de poesía mellor ilustradas que coñecemos, dunha estética moi atractiva a ela debida, tantas veces empregando ilustracións da súa man, como excelente pintora que é na realidade. Menos coñecemento tiñamos da obra artística de José Valentín, aínda que a nosa primeira impresión era certamente boa: debíase ao libro Atmosferas, con poemas de Olga Patiño e gravados de José Valentín, publicado en 2007, claro precedente, na súa concepción formal, de Deter o día cunha flor.

A mellor información que achamos sobre José Valentín (nome artístico de José Valentín Díaz Germade) aparece na lapela posterior do libro, que non sabemos a quen se debe. Despois de sinalar que naceu en Betanzos, en 1942, indícanos:

José Valentín descobre aos sesenta anos o mundo do gravado, tras entrar en contacto co Centro Internacional de Estampa Contemporánea de Betanzos, onde coñece ao seu mentor, Jesús Núñez. Baixo a súa tutela e amizade inicia unha carreira de produción propia. Obviando o figurativo, mergúllase na abstracción: un universo de explosión colorista, de xogo sensual entre a profusión de liñas, a profundidade das texturas e a omnipresencia do círculo. Decide entón levar a cabo unha actividade frenética, con sucesivas exposicións en diversos puntos de Galiza, Portugal e Alemaña. Ten flirteado coa poesía, realizando unha exposición conxunta coa poeta Olga Patiño Nogueira, e nesa liña publica con ela o libro Atmosferas, obra de diálogos entre a palabra e a imaxe. (...) José Valentín revélase como un artista de vocación tardía que xorde coa creatividade dun talento novo e a experiencia vital dun home maduro.

As dúas partes constitutivas de Deter o día cunha flor son perfectamente separables, como demostra o feito de que os textos da parte terceira e cuarta, como imos ver de seguida, xa foran publicadas previamente por Luz Pozo Garza,

\footnotetext{
${ }^{1}$ Á espera da edición do poemario que leva por título Sol de medianoche. Natalia fiel memoria (no prelo), Deter o día cunha flor segue a ser de momento o último libro de Luz Pozo Garza. Este artigo que publicamos quere ser un anticipo do noso libro sobre a meirande figura das letras galegas de hoxe en día $A$ procura da poesía. Vida e obra de Luz Pozo Garza, en trámite de edición.
} 
sen os gravados de José Valentín. No entanto, parece indubidable que na conxunción das poesías e dos gravados do libro, en harmonía sorprendente, reside a causa dun resultado fascinante, unha peza artístico-literaria dunha beleza verdadeiramente máxica.

\section{AS CATRO PARTES DO POEMARIO}

Deter o día cunha flor consta de catro partes que, malia ser moi distintas tanto polo contido como polo momento da súa composición, orixinan un todo moi coordenado, case como se todas elas fosen concibidas para esta obra, cousa que realmente non foi así.

A parte primeira, provista dun nome moi significativo, "Aleph", está composta por once poemas, moitos deles con títulos que falan por si mesmos: "Vestixio", "Corazón", "Aleph", "Vía Sacra", "A Face de Deus", "Soñar a neve", "Descalza", "Corpo diamantino", "Graal", "Pléyades", "Ferido Paradiso", "Alma miña, ¿que arelas?”. O denominador común reside na procura do Aleph, como confesa a poeta mesmo abertamente: "A procura do Aleph pola perfecta vía / da luz / andei na noite milenaria" (poema "Descalza"), concepto misterioso, máxico, no que, tal como no famoso relato de Borges ${ }^{2}$, se reflicte todo o Universo, porque todo o Universo é un reflexo seu. Desde as primeiras obras de Luz Pozo Garza, maniféstase decote a preocupación por todo tipo de verdades, mais por antes que outras das profundas verdades da nosa existencia, que cómpre descubrir, analizar, explicar, nos diversos aspectos das realidades da vida, malia estar a poeta dende sempre animada por unha relixiosidade e unha fe firmes. Nas cousas, nos seres vivos, nas palabras coas que os denominamos, nas persoas, nos sentimentos, busca Luz Pozo Garza ao longo de poemas dunha sorprendente madureza, profundidade, sinceridade, e beleza, o Aleph, o conxunto das verdades da existencia, "a raizame do ser", en palabras súas. Velaí, a modo de exemplo, o poema "Aleph", dedicado a Xosé Tomás:

Que importa se perdemos

o conflicto das horas

os traballos e os días ou as flores do mal agora non hai tempo nin espazo absolutos nin partículas sólidas de índole elemental

Hai outras magnitudes que achegan o misterio Bogando mar adentro descubrimos o Aleph as illas oceánicas as praias diamantinas os mitos que perviven na raizame do ser

Arelas que nos levan sen saber onde imos á deriva da vida Vin a Face de Deus A Face de Deus A Face de Deus.

A segunda parte, "Li Yián pide deter o día", é un conxunto de trece poemas inspirados na poeta chinesa Li Yián, da que Luz Pozo Garza, partindo de moi poucos datos e dun só poema, constrúe unha visión abondo imaxinaria, pero con fermosas intuicións, que fan desta parte do libro unha pequena obra mestra, dunha fineza e beleza dificilmente imaxinables.

Quen foi Li Yián? Na realidade, prescindindo por completo de momento do que podemos ler en Deter o día cunha flor, Li Yián, con moito maior frecuencia coñecida polo nome Li Qingzhao, foi unha poeta chinesa do século XII, nada en concreto en 1084 en Li Cheng, actual Jinang, na provincia de Shandong. Malia ser recoñecida universalmente como a mais grande cultivadora da poesía chinesa, non xa dunha época tan temperá como aquela en que viviu, senón de todos os tempos, pouco sabiamos dela ata a última década, en que boa parte da súa escrita foi traducida directamente do chinés ao español pola sinóloga Pilar González España, que ten o mérito de ter publicados tres libros con poemas de $\mathrm{Li}$ Qingzhao nos anos 2003, 2010 e 2011, e tamén o non menos importante de ter dado noticia dela e da súa obra nos últimos dez anos, en moi diversos foros de interese cultural e literario. Da documentadísima información que nos achega

${ }^{2}$ Borges (1949); cfr. especialmente o relato que da título ao volume. 
González España imos escolmar tres curtas pasaxes para unha visión rápida da poeta:

$\mathrm{Su}$ origen ilustre y una educación intelectual y artística forjaron el espíritu de esta mujer que no abandonaría jamás la poesía a lo largo de toda su vida. A pesar de lo excepcional de la situación (una mujer escritora en la China del s. XII), su calidad y maestría literarias convencieron a todos los historiadores y letrados, tanto del pasado como del presente, de que se trataba, sin lugar a dudas, de la más extraordinaria mujer poeta de toda la historia de la poesía china.

El núcleo temático y vital de Li Qingzhao fue el amor, un amor que se extendió y modificó, siguiendo el periplo de su vida y su corazón. (...) Ella y su marido Zhao Mingcheng (1081-1229), bibliófilo, coleccionista y de una gran cultura, compartieron la creación poética y el trabajo de erudición (compusieron ambos un Catálogo de inscripciones en metal y piedra). Con los libros que se compraron llenaron más de diez salas de su casa, y se dedicaban a leerlos, hacer pruebas de memoria, escribirse poemas el uno al otro... (González España 2010: 10-11)

Polo que respecta á poesía do xénero $c i$, na que Li Qingzhao escribiu a meirande parte da súa poesía (aínda que non toda), de novo empregamos, faltos de outra preparación, as explicacións de Pilar González España:

$C i$ significa, literalmente, "canción-palabra". Se trata de un poema compuesto para una melodía existente, aunque hoy en día ya perdida. Era una forma popular en la dinastía Tang (618-907), pero, a partir del s. X, durante la dinastía Song, se convirtió en uno de los más importantes géneros poéticos, consiguiendo acabar definitivamente con el esquema rígido de la poesía regular de cuatro u ocho versos (lüshi у jueju). (2010: 14)

Dada esta sucinta información ${ }^{3}$, que na actualidade é fácil de ampliar, especialmente coa lectura da non abundante obra de Li Quingzhao, imos ver o que sabía dela Luz Pozo Garza cando escribiu os poemas de "Li Yián pide deter o día". O primeiro poema, titulado "Limiar", ofrece datos magníficos sobre este asunto:

Ela existiu no século XI
na Dinastía Tang ${ }^{5}$ naquel País de Seda
Poeta admirada segundo
$\quad$ fidedignas noticias...

No libro onde a leo

hai tan só un único poema polo que a coñecín:

desde o pavillón das doncelas contempla unha flor que naceu na súa fiestra. A flor chámase lascivia de primavera

E todo semella símbolo do amor. Nese amencer que a inquieta aloumiña o laúde mais non hai melodía Só nostalxia e ausencia...

O máis incisivo do poema son as palabras de soidade e de impotencia

cando fala coas plantas: "xa sei que non podes deter o día".

\footnotetext{
${ }^{3}$ Á que cumpriría engadir polo menos algunhas notas sobre a gran modernidade, aínda desde a perspectiva dos nosos días, da poesía de Li Qingzhao. Recordaremos a este propósito unhas palabras da recensión da tradución española de 2010 feita por José Ángel Cilleruelo, que poden verse en www.elciervo.es $/ \mathrm{html} / \mathrm{default}$. asp?/iea=libros\&libro=287: "Cuenta Pilar González España, editora y traductora de esta Poesía Completa de Li Qingzhao (1084-1140), que en cierta ocasión el marido de la poeta incluyó entre cincuenta poemas escritos por él unos versos de su mujer: «¡no digas que el alma / no sabría languidecer de amor! / tras las cortinas / que el viento del oeste ondea / ella aparece tan grácil / como un crisantemo». Un amigo que los leyó no dudó en destacar estos como los mejores del conjunto. No es una anécdota que resulte lejana. Si algún poeta culturalista los hubiera copiado entre los suyos, posiblemente el lector de hoy los destacaría igualmente. Una de las virtudes de la poesía china clásica es esta capacidad de contemporaneidad, sorprendente en poetas de la Dinastía Tang como Li Bai o Du Fu y también en la obra de Li Qingzhao: motivos, tonos, imágenes, sensibilidad e incluso la práctica de la intertextualidad parecen más actuales que concebidos hace casi mil años".

${ }^{4}$ Como sen dúbida se terá notado, non damos número de páxinas nas nosas referencias a este libro, porque Deter o día cunha flor carece de paxinación.

${ }^{5}$ En realidade a poeta nace no século XI, pero vive fundamentalmente no XII, e non na Dinastía Tang, mais na Dinastía Song. Son erros de Luz Pozo Garza, xustificables pola súa limitada información, que non afectan para nada á súa poesía sobre a escritora chinesa.
} 
Ao pé da páxina, malia non ter notas o libro, lemos esta aclaración: "Nestas verbas finais me inspirei / para escribir o poemario LI YIAN OU / DETER O DÍA CUNHA FLOR"; todo o que confesa é certo, porque Luz Pozo Garza coñeceu a poeta única e exclusivamente polo libro Historia de la Literatura universal de Martín de Riquer e José María Valverde (1986). En efecto, no volume $\mathrm{X}$, debido a Valverde, no capítulo que toca as literaturas de China e Xapón, escribe: "Y situamos también aquí a una gran poetisa, Li Qingzhao (o Li Yian, nacida en 1082), que en sus composiciones presenta la experiencia femenina con todas sus frustraciones y limitaciones propias de aquel contexto social. Con ella rivaliza otra gran poetisa de entonces: Zhao Zhuseng" (Riquer / Valverde 1986: X, 476). E dende esta breve explicación envía á parte antolóxica, onde ofrece un exemplo, baixo o epígrafe "Li Qingzhao o Li Yian, Poema":

En mi estrecho cuarto de ancha ventana hay [una lascivia de primavera.

A través de las cortinas sin correr se entrevén [confusas sombras:

mientras yo, en el pabellón, acaricio mi laúd [ornado de jade rosa,

se ve el cerro en la tenue claridad del amane [cer que se apresura.

Flor del pimiento, ¿por qué te inclinas pidien [do perdón?

Ya sé que no puedes detener el día ${ }^{6}$.

Isto é toda a información e os únicos versos de Li Qingzhao que coñecía Luz Pozo Garza cando escribiu os seus trece poemas sobre a poeta chinesa, segundo confesa, como vimos, no primeiro deles, e segundo nos confirmou en conversa telefónica cando estabamos a escribir estas páxinas. E sen saber tantas outras cousas doadas de coñecer, sobre todo agora, que xa temos versións ata en español, a poeta de Ribadeo concibe unha imaxe da poeta de Jinang, e sen mais datos que eses versos en que Li Qingzhao recorda a flor chamada lascivia de primavera e fala coa flor do pementeiro, crea a imaxe dunha fermosa rapaza namorada, que canta amores e penas de ausencias, soidades, nun escenario típico chinés, elegante, con finos aromas, e sempre con flores; flores que, aínda que Luz non podía sabelo, son mais que ningunha outra a flor da ameixeira, e a magnolia, o loto, a flor da pereira, a flor de ouro ou crisantemo, a flor da canela, as rosas, os xeranios... Entón, ¿unha daquelas que cantan as pombas e as flores? Non precisamente: o mesmo que moitísimos séculos despois Luz terá a súa poesía sementada de flores, Li Qingzhao enche os seus poemas de flores, pero o seu tema fundamental é o amor, o amor en si mesmo e o amor por un home, na presenza, na ausencia, e despois na ausencia definitiva, cando morre Zhao Mingchen en 1129 e, xa viúva, segue ela, na lembranza, a escribir poemas.

Flores, cores, perfumes; a primavera, e tamén o outono; o amencer e a tardiña; e decote a lembranza do namorado, e a lúa, sempre a lúa, como en Safo: "a lúa alumea o valeiro do meu leito", lamenta Li Qingzhao. E Luz Pozo Garza, sen saber a meirande parte destas cousas, pero coa intuición poética que os antigos lle presupoñían aos grandes poetas cando lles chamaban vates, tece un breve poemario, que pensou chamar "Li Yián ou deter o día cunha flor", no que hai poemas tan inspirados como o seguinte, titulado "Aves sagradas":

Móstrase o sol divino na hora propicia do Celeste imperio

Pasan as aves que nos viron xuntos collidos polo van

\footnotetext{
${ }^{6}$ En nota lemos: "Versión indirecta de J. M. Valverde". Este poema non está entre os publicados por Pilar González España; en troques, atopamos en Internet unha versión de Juan Carlos Villavicencio, que presenta algunhas diferenzas: "En mi angosto cuarto, donde amplia se abre mi ventana, / reinaba profunda una primaveral lascivia. / A través de las oscilantes cortinas aún no levantadas, / confusas sombras aparecen, / Mientras yo, oculta en la casa de verano, acariciaba / mi laúd de jade rosa. / A lo lejos cae un farellón de la montaña, / mientras la claridad cede ante el ocaso que comienza. / Suave el viento sopla una tenue lluvia, delicada como / la caída de una sombra. / ¡Oh, flor del pimiento! No necesitas inclinarte para pedir perdón: / Sé que no puedes detener el día".
} 
Aquelas aves moran no absoluto do cosmos

e retornan nas auras cada día

—Ou! Li Yian... Ou! Li Yian

"Flor de ausencia" ferida...

con chíos fulgurantes

van chamando por nós

para deter o tempo:

nun oficio de voces que nunca se escoitaron no concerto sagrado da existencia "amor amor" dicían.

Xa rematando a curta colección de poemas, Luz Pozo Garza, sen esquecer nunca a Li Yian, torna no pensamento a Galiza, as costas do seu Ribadeo natal, no fermoso poema "Praia das catedrais", onde suplica deter o tempo, e que Li Yian non se afaste dela. Pero a poeta chinesa marcha, e Luz recorda esa nai poética sempre presente na súa poesía que é Rosalía de Castro, como revela abertamente nas palabras "envío a Rosalía", pequenas e case imposibles de ler no fondo negro da páxina, ao final do último poema, "A poetisa Li Yian despídese do espazo dos seus soños":

Adeus soles adeus lúas
adeus soñares desperta
soños de divina estirpe
recollidos na consciencia
un libro leva a outro espazo
un soño leva a outro soño
a materia sendo ambigua
revela a imaxe do cosmos

ai AMOR

detén o tempo aleve cunha flor.

A parte terceira titulase "Lotus no corazón", e a clave vén dada pola dedicatoria inicial: "a Eduardo, sempre". Trátase, en efecto, de trece poemas copiados, con moitos cortes e moi poucos cambios, do poemario Prometo a flor de loto, que fora escrito, como recordamos no seu momento, despois do falecemento de Eduardo Moreiras, en abril de 1991, e publicado en 1992. Tendo en conta que a edición deste poemario foi moi reducida, como nos ten referido varias veces a poeta, non deixa de ser unha sorte ter unha parte dos poemas de novo impresa, agora ademais cos fermosos e orixinais gravados de José Valentín; porén, cómpre advertir que a redución dos poemas e os cortes a que foron sometidos fai que non podan suplir de ningunha maneira ese gran libro que é Prometo a flor de loto, unha das obras mestras e máis sentidas de Luz Pozo Garza.

A cuarta e última parte de Deter o día cunha flor consta dun único poema, "Carta de Beatrice Vía-Láctea", dedicado a Carmen Blanco e Claudio Rodríguez Fer, de modo idéntico a cando apareceu por primeira vez, ao comezo do volume VI de Clave Orión, no Ano Xacobeo de 1999. A base argumental, a subida de Dante ao Paradiso xunto coa namorada Beatrice, tan maxistralmente relatada no Canto I da Divina Commedia, xa fora moito antes poetizada no poema "Na súbita compaña" de Códice Calixtino (1991):

Cando asumen as sombras escuras violetas
nun xardín meditado
pode ser só un símbolo o tributo de Dante
subindo ó Paradiso
na súbita compaña. (Pozo Garza 1991: 86)

A idea de rematar un poemario formado por catro partes tan distintas co poema da "beatífica fuga celeste" de Dante e Beatrice dá moito que pensar. Os libros de poesía de Luz Pozo Garza non son practicamente nunca unha mera colección de poemas xuntados para facer un libro, senón que acostuman seguir unha liña argumental ben deseñada e desenvolvida. Deste modo, na parte terceira de Deter o tempo cunha flor, o último poema, a despedida da poeta Li Yian ou Li Qingzhao, de súpeto inclúe dous versos inesperados, "a materia sendo ambigua / revela a imaxe do cosmos", que nos levan á cerna ideolóxica do Aleph. Daquela, cando incluíu para rematar o conxunto do libro esta viaxe final de Dante e a súa amada, que xa fora composta e publicada moitos anos antes, non pensou Luz Pozo Garza na tanta veces comentada resonancia de Dante e Beatrice nos curmáns Carlos Argentino Daneri e Beatriz Vitervo, protagonistas con Borges do relato "El Aleph"? Non comentamos esta posibilidade coa poeta, porque un libro só nunca será abondo para desvelar todas as claves da súa poesía, construída sobre unha exquisita sensibilidade poética, pero cimentada tamén sobre unha admirábel cultura literaria.

Para rematar, pensamos que pode ser proveitoso editar unha vez mais o poema, fermoso mesmo sen as ilustracións de José Valentín: 
...foi entón cando Dante me tomou polo van na idea beatifica dunha fuga celeste moi secreta pero que se anunciaba nos máis altos designios [das esferas

Mentres me arrebataban unha luz moi preclara como de rosas nosas dun tacto indefinido chegaba destinada do sínodo celeste e vin soles [e lúas

o espírito da luz sobre un vieiro santo que remata no espacio das fisterras e vin pontes e cúpulas e [tebras

moi sutís e o derradeiro río semellantes a unha [cítara

e unha flor diamantina e a entidade da morte e o enigma das palabras nun códice miniado e a conspiración última da saudade preto de [Compostela

E todo se tornaba en himnos e pregarias nunha chama solemne de profundis e coros de [te deum

que desgaxaba a alma e facía chorar de benaven[turanza

E pasaba unha luz como de lumarada por enriba [dos ollos

E nunha voz unánime as mil linguas soletreaban [o ultreia

camiño de Santiago

E revelouse en min a comunión das almas e as vida dun delirio perdurable e acordei coa doctrina clemente da memoria

Amor que me levabas na evolución do liño na [posición do lume

O meu Dante está morto baixo dun alcipreste no fondal dalgún claustro en penumbra dunha [aldea perdida

Aínda gardo a gozosa visión daquel libro que [canta a nosa vida

iba escrito en memorias de luz en outonos de [amor

Amor que move o sol e outras estrelas...

E agora que vou dando ó vento o meu lamento e chove lentamente como levar unha ave na [mirada en tempos de infortunio camiño de Santiago

Vólvome ó Paradiso Vólvome ó Paradiso Vólvome ó Paradiso.

\section{DÚAS NOTAS SOBRE A RECEPCIÓN DE DETER O DÍA CUNHA FLOR}

Deter o día cunha flor, poemario que chama inmediatamente a atención pola súa harmoniosa edición, foi obxecto de importantes presentacións na primavera de 2009 , destacando as que tiveron lugar en abril, na Fundación Caixa Galicia da Coruña, coa presenza da autora e do gravador, coas intervencións de Ánxeles Penas e Xulio Valcárcel, e co recitado de poemas do libro a cargo de Olga Patiño; e na Galería Sargadelos de Lugo, na que falaron Carmen Blanco e Claudio Rodríguez Fer.

A comezos do ano 2010, obtivo a distinción de "Libro Galego do Ano 2009", outorgado polos lectores de El Progreso de Lugo. Así comezou a ser distinguida por unha serie de galardóns, entre os que cómpre salientar o correspondente a poesía dos que convoca cada ano a Asociación de Escritores en Lingua Galega (AELG). No mes de abril acadou o prestixioso "Premio de la Crítica", concedido pola Asociación Española de Críticos Literarios, que na sección galega deron o premio de narrativa a $O$ cabo do mundo, de Xabier Quiroga, e o premio de poesía a Deter o día cunha flor, de Luz Pozo Garza. Na noticia sobre o premio difundida pola prensa podemos ler:

Xosé Manuel Eyré ha alabado a la obra gallega ganadora en narrativa, El cabo del mundo, de Xabier Quiroga, de la que destacó que es una "lograda creación literaria" para que no se olviden "los desastres provocados por el alzamiento militar franquista", y ha alabado la exquisitez literaria de Detener el día con una flor, de la poeta Luz Pozo Garza?

No mesmo ano foille entregado en Sarria (Lugo) o premio Irmandade do libro, outorgado pola Federación de Libreiros Galegos.

\section{LUZ POZO GARZA: VISIÓN PERSOAL DE DETER O DÍA CUNHA FLOR}

O libro Deter o día cunha flor consta de tres breves introducións escritas por Claudio Rodríguez Fer, Carmen Blanco e Xulio Valcárcel,

\footnotetext{
${ }^{7}$ Segundo Publico.es Diario Publico (17/4/2010).
} 
e os meus versos, en catro apartados: 1. Aleph (dez poemas); 2. Li Yián pide deter o día (doce poemas); 3. Lotus no corazón (doce poemas); 4. Carta de Beatrice vía-láctea (catro poemas).

1. De Aleph publicárase algún poema en revistas. Non recordo exactamente onde. A meirande parte, inédito. Semella que andaba eu na procura dunha nova espiritualidade sen deixar lonxe de min os íntimos e acariñados mitos do lotus e da rosa, das illas de outrora. Sentíame vital, reclamaba o amor intacto, a vida, a vida, a vida. A felicidade das aves no sagrado principio de voar. E toda eu, nesa unidade cósmica da conciencia, suplicáballe á miña alma contemplativa que rubricase cun corazón humano as cousas esenciais que procuro: o amor, a liberdade, un canto emocionado e a divina arelanza.

No principio, claro está, asumo a ficción borgiana da simultaneidade da visión do Aleph, ese lugar onde están todos os lugares da terra, sen confusión nin transparencia. Sempre estiven obsesionada co libro de Borges. Non tratei de imitar o inimitable, pero quedou en min a intención, aínda imborrable, da idea de ensoñar enigmas e lugares imposibles... mesmo a Face de Deus... polo que deixei a Vía Augusta e seguín a Vía Sacra, pero os salmos cantaban na Aleluia amor, amor por sempre... e na Face de Deus, nunha inmóbil mudanza, morte e vida en paradoxo sempre, o amor ficaba inscrito nun símbolo mandálico e Deus falaba órbitas e tebras e a pobre alma era incapaz de comprender palabra...

Hai xa nesta obriña unha idea de extravío, de perda do camiño ou falta dunha guía que leve aos pazos do misterio. O que alude ás miñas raíces. No mesmo sentido obran as expresións de andar descalza na noite milenar de cara ao pazo dunha luz acesa nas altísimas vidreiras... Precedentes da obra actual: Pazo de Tor ${ }^{9}$ que nin sequera o tiña concienzado pero ben se intúe que obraba no subconsciente. Máis adiante hai tamén unha gozosa revelación que concibe o ser.
E todo o espazo lírico se transforma e festexa: "A Rosa é a miña alma"...

2. Li Yan pide deter o día foi escrito especialmente para este libro. O idilio amoroso dos xoves amantes chineses está inspirado nun único poema coñecido por min da admirable poetisa Li Yan, do século XI. Fala ela -como a nosa Rosalía- coas plantas. Inutilmente quixera ela deter o tempo do amor, pero acepta a realidade con resignación e tristeza. Baseada neste breve e delicado indicio, construín con facilidade o poema total dos amantes nun espazo idílico que me era moi afín. Encantábame modular con sinxeleza e finura aqueles entornos de acordo cos sentimentos dos namorados.

Ao final do conxunto poético, cando o xardín das orquídeas de inverno ou o estanque dos lotos puros a penas se respiran aire fresco, de tanta concentración versal, abrín as portas chinesas de cara ás praias frías da Mariña lucense onde as parellas míticas se aman. Praia das Catedrais. Paradiso...

E xa con nós, non podía faltar unha mensaxe implícita a Rosalía: “Adiós soles adiós lúas / adiós soñares desperta...". E ela mesma, Rosalía, detén o tempo aleve cunha flor.

3. Lotus no corazón -a Eduardo semprereúne unha breve selección de poemas, en fragmentos, do libro Prometo a flor de loto, de 1992. Probablemente sexan os máis coñecidos ou valorados polos lectores...

4. Carta de Beatrice vía-láctea, un dos meus poemas favoritos -adicado a Carmen e a Claudio- pecha o volume. A carta de Beatrice, coido eu, constitúe unha peza fundamental no grupo dos meus poemas - plaquette, aqueles que por si mesmos teñen entidade propia.

Dentro da temática itinerante do Xacobeo, a visión mística dun Aleph planea sobre o espazo consagrado do vieiro santo. Vin a flor diamantina e a entidade da morte. Mil linguas cantan Gloria. Co meu Dante, en fuga beatífica, imos

\footnotetext{
${ }^{8}$ Este texto foi escrito por Luz Pozo Garza a petición nosa, o día 26 de febreiro de 2013.

${ }^{9}$ Refírese Luz Pozo Garza a un novo poemario que compón na actualidade (2013), titulado Pazo de Tor, polo pazo preto de Monforte de Lemos co que ten relacións de familia por antepasados maternos
} 
arrebatados por unha luz secreta entre soles e lúas. E todo se me revela, mesmo a súa morte no fondal dalgún claustro.

Hai neste poema que eu amo, claros indicios de profecía. Chéganme visións que nestes mesmos intres se están a cumprir en Compostela:
Non parece anunciarse aquí o secuestro do Códice Calixttino con toda a parafernalia que se formou ao seu redor?

Vin...

o enigma das palabras nun códice miniado e a conspiración última preto de Compostela.

\section{REFERENCIAS BIBLIOGRÁFICAS}

Borges, Jorge Luis (1949): El Aleph. Buenos Aires: Losada.

González España, Pilar (trad.) (2003): Li Qingzhao. Poemas escogidos. Málaga: Servicio de Publicaciones de la Diputación Provincial.

- (trad.) (2010): Li Qingzhao. Poesía completa (60 poemas ci para cantar) (edición, tradución do chinés e notas). Guadarrama (Madrid): Ediciones del Oriente y del Mediterráneo.

(trad.) (2011): Li Qingzhao. La flor del ciruelo (prólogo e tradución). Madrid: Ediciones Torremozas.

LóPEz, Aurora / Andrés PociÑa (2013): Á procura da poesía. Vida e obra de Luz Pozo Garza. Libro en trámite de edición.

Patiño, Olga / José Valentín (2007): Atmosferas (prólogos: Miguel Anxo Fernán Vello, Manuel Silvestre Visa; fotografía: Alba González Patiño, Noa González Patiño, Gustavo Ros Allain, José Tomás). A Coruña: Deputación.

Pozo Garza, Luz (1991 [1986]): Códice Calixtino (ed. Carmen Blanco). Vigo: Xerais.

Pozo Garza, Luz (1992): Prometo la flor de loto (ilustracións: Urbano Lugrís). A Coruña: Deputación (Col. de Poesía 2).

Pozo Garza, Luz (2013): Sol de medianoche. Natalia fiel memoria (no prelo).

Pozo Garza, Luz (2013): Pazo de Tor (en preparación).

Pozo Garza, Luz / José Valentín (2009): Deter o día cunha flor (deseño: Xosé Tomás; preliminares: Claudio Rodríguez Fer, Carmen Blanco e Xulio Valcárcel). A Coruña: Baía.

Riquer, Martín de / José María Valverde (1986): Historia de la literatura universal. Barcelona: Planeta, 10 vols.

VAlCÁRcel, Xulio (2009): “Dualidade harmónica”, en Luz Pozo Garza / José Valentín, Deter o día cunha flor. A Coruña: Baía (sen paxinación). 